infection is caused by a novel cluster of Emmonsia-like species (1); involves fungemia; appears to be associated with immunosuppression, including renal transplant (7-9) and orthotopic liver transplantation and HIV (10); and has a high case-fatality rate.

The timing of this infection raised concern for a donor-derived infection. However, we confirmed with the United Network for Organ Sharing (https://www.unos. org/) that no other organ recipients from the same donor had a similar posttransplant infection. Reported soil and rodent exposure for the patient and previous granulomatous disease identified by pretransplant chest imaging raised the possibility that his infection was a reactivation of a latent infection.

The unfamiliar mold isolated from the patient's pleural fluid was initially identified as a contaminant, and the patient died despite favorable in vitro antifungal susceptibilities. In immunosuppressed patients with a compatible clinical syndrome, fungi isolated from a sterile site should be identified. More cases of Emmonsia-like infections will probably be diagnosed as laboratories use sequencing to identify uncommon fungal pathogens.

Dr. Kappagoda is a clinical assistant professor at Stanford University School of Medicine, Stanford, CA. Her research interests are neglected tropical diseases and endemic fungal infections.

\section{References}

1. Schwartz IS, Kenyon C, Feng P, Govender NP, Dukik K, Sigler L, et al. 50 years of Emmonsia disease in humans: the dramatic emergence of a cluster of novel fungal pathogens. PLoS Pathog. 2015;11:e1005198. http://dx.doi.org/10.1371/journal. ppat. 1005198

2. Anstead GM, Sutton DA, Graybill JR. Adiaspiromycosis causing respiratory failure and a review of human infections due to Emmonsia and Chrysosporium spp. J Clin Microbiol. 2012;50:1346-54. http://dx.doi.org/10.1128/JCM.00226-11

3. Kenyon C, Bonorchis K, Corcoran C, Meintjes G, Locketz M, Lehloenya $\mathrm{R}$, et al. A dimorphic fungus causing disseminated infection in South Africa. N Engl J Med. 2013;369:1416-24. http://dx.doi.org/10.1056/NEJMoa1215460

4. Schwartz IS, Govender NP, Corcoran C, Dlamini S, Prozesky H, Burton R, et al. Clinical characteristics, diagnosis, management, and outcomes of disseminated emmonsiosis: a retrospective case series. Clin Infect Dis. 2015;61:1004-12. http://dx.doi.org/10.1093/ $\mathrm{cid} / \mathrm{civ} 439$

5. de Almeida Barbosa A, Moreira Lemos AC, Severo LC. Acute pulmonary adiaspiromycosis. Report of three cases and a review of 16 other cases collected from the literature. Rev Iberoam Micol. 1997; 14:177-80.

6. England DM, Hochholzer L. Adiaspiromycosis: an unusual fungal infection of the lung. Report of 11 cases. Am J Surg Pathol. 1993; 17:876-86. http://dx.doi.org/10.1097/00000478-199309000-00003

7. Feng P, Yin S, Zhu G, Li M, Wu B, Xie Y, et al. Disseminated infection caused by Emmonsia pasteuriana in a renal transplant recipient. J Dermatol. 2015;42:1179-82. http://dx.doi.org/ $10.1111 / 1346-8138.12975$

8. Heys I, Taljaard J, Orth H. An Emmonsia species causing disseminated infection in South Africa. N Engl J Med. 2014;370:283-4. http://dx.doi.org/10.1056/NEJMc1314277

9. Sanche S, Wong A, Sigler L, Angel S, Peterson S. Invasive infection caused by a novel Emmonsia species in a renal transplant patient. In: Abstracts of Focus on Fungal Infections 2005. Miami (FL); 2005. Abstract 87 [cited 2016 Nov 10]. http://www.mycosesstudygroup.org/educatio/conf_highlights/ focus15/index.htm

10. Pelegrín I, Ayats J, Xiol X, Cuenca-Estrella M, Jucglà A, Boluda S, et al. Disseminated adiaspiromycosis: case report of a liver transplant patient with human immunodeficiency infection, and literature review. Transpl Infect Dis. 2011;13:507-14. http://dx.doi.org/10.1111/j.1399-3062.2011.00611.x

Address for correspondence: Shanthi Kappagoda, Division of Infectious Diseases and Geographic Medicine, Stanford University School of Medicine, 300 Pasteur Dr, Lane Bldg, Rm L154, Stanford, CA 943055107, USA; email: skappago@stanford.edu

\title{
Outbreak of Legionnaire's Disease Caused by Legionella pneumophila Serogroups 1 and 13
}

\section{Toshiro Kuroki, ${ }^{1}$ Junko Amemura-Maekawa, ${ }^{1}$ Hitomi Ohya, Ichiro Furukawa, Miyuki Suzuki, Tomoka Masaoka, Kastuhiro Aikawa, Kazumi Hibi, Masatomo Morita, Ken-ichi Lee, Makoto Ohnishi, Fumiaki Kura}

Author affiliations: Kanagawa Prefectural Institute of Public Health, Kanagawa, Japan (T. Kuroki, H. Ohya, I. Furukawa, M. Suzuki, T. Masaoka, K. Aikawa, K. Hibi); National Institute of Infectious Diseases, Tokyo, Japan (J. Amemura-Maekawa, M. Morita, K. Lee, M. Ohnishi, F. Kura)

DOI: http://dx.doi.org/10.3201/eid2302.161012

In Japan, hot springs and public baths are the major sources of legionellosis. In 2015, an outbreak of Legionnaires' disease occurred among 7 patients who had visited a spa house. Laboratory investigation indicated that L. pneumophila serogroup 1 and 13 strains caused the outbreak and that these strains were genetically related.

$\mathrm{I}^{\mathrm{r}}$ nfection with Legionella bacteria is one of the major causes of community-acquired pneumonia (1). In Japan, the major sources of Legionella infection are hot springs and public

${ }^{1}$ These authors contributed equally to this article. 
baths (2). Among Legionella species, L. pneumophila serogroup 1 accounts for most human infections (3). Legionellosis outbreaks caused by a combination of $L$. pneumophila serogroup 1 or other serogroups have rarely been reported. We report an outbreak of Legionnaires' disease caused by $L$. pneumophila strains of serogroup 1 and serogroup 13.

During June 1-17, 2015, the Health Centers in Kanagawa and Shizuoka Prefectures, Japan, were notified of 7 cases of Legionella pneumonia. All patients with pneumonia were admitted to 1 of 5 hospitals. All patients were male (mean age 66.3 years), 4 had diabetes mellitus, and 1 had hepatic cirrhosis and liver cancer. Diagnosis of pneumonia at the hospitals was based on clinical presentation and immunochromatographic detection of $L$. pneumophila serogroup 1 antigen in urine. All patients recovered and were discharged.

In epidemiologic interviews, all 7 patients stated that they had visited a spa house in Odawara, Kanagawa, Japan, before illness onset. The latent period was not accurately determined because 5 of the 7 patients frequently visited this spa house and some patients had visited it again after illness onset. The spa house had 7 circulating systems, including filtration and heating components, and 9 baths for men.

Sputum samples from 5 urinary antigen-positive patients and environmental samples from the spa house were collected for epidemiologic investigations and cultured for Legionella at the Kanagawa Prefectural Institute of Public Health. L. pneumophila serogroup 1 was detected in sputum from 4 patients (Table), and L. pneumophila serogroups 1 and 13 were detected in sputum from 1 patient (patient 2). Baths $1-5$, but not baths 6-9, contained $L$. pneumophila. Epidemiologic investigation and laboratory results revealed that failure to adequately chlorinate the bath water and the circulating systems resulted in colonization of Legionella at the spa house.
Pulsed-field gel electrophoresis (PFGE) comparison (4) of clinical and environmental isolates revealed that the L. pneumophila serogroup 1 strains produced 3 PFGE profiles: A and B, with a 1-band difference, and C (Table). Patient 7 was infected with $2 \mathrm{~L}$. pneumophila serogroup 1 isolates possessing PFGE profiles A and B. The PFGE profile B of L. pneumophila serogroup 13 was identical to that of serogroup 1 . We determined the sequence type (ST) of L. pneumophila strains $(5,6)$ and identified 4 new STs: ST2113, ST2114, ST2115, and ST2121. ST2114 differed from ST2121 by only $1 \mathrm{nt}$ in $n e u A$ and differed from ST2113 (serogroup 13) by only 2 alleles (mip and neuA), suggesting that these 3 STs are closely related and that 1 of 3 strains (ST2113, ST2114, or ST2121) may be derived from another by homologous recombination. All examined isolates lacked the lag- 1 gene, a virulenceassociated marker (7).

By using whole-genome sequencing, we applied coregenome multilocus sequence typing (cgMLST) with 50 genes (8) different from the 7 genes in sequence-based typing, thereby confirming the sequence-based typing data (Table). ST2114 and ST2115 isolates were each divided into 2 cgMLST profiles. cgMLST profile $b$ differed from profile a by only $1 \mathrm{nt}$ on $\operatorname{lpg} 1503$ and differed from profile d by $5 \mathrm{nt}$ on $\operatorname{lpg} 0812$, near the lipopolysaccharide coding region, suggesting that the strain of profile $d$ may be derived from another by homologous recombination. However, the remaining cgMLST profiles (c, e, and f) from strains not isolated from patients differed from profile $b$ by 30,42 , and 43 alleles, respectively.

Multiple L. pneumophila strains with different genetic characteristics exist in the environment and pose infection risks (9). Among the strains studied, dual infections with $L$. pneumophila serogroup 1 and serogroup 13 strains (patient 2 ) and $L$. pneumophila serogroup 1 strains with different

\begin{tabular}{|c|c|c|c|c|c|}
\hline Serogroup & PGFE profile† & STf & $\begin{array}{l}\text { ST profile, flaA, pile, asd, mip, } \\
\text { momps, proA, neuA }\end{array}$ & Sample source & $\begin{array}{l}\text { cgMLST } \\
\text { profile§ }\end{array}$ \\
\hline 1 & $A$ & ST2114 & $6,10,21,3,17,14,9$ & $\begin{array}{l}\text { Patients 1, } 7 \\
\text { Bath } 1 \text { (bath water)ף } \\
\text { Bath } 2 \text { (spout swab) }\end{array}$ & $\begin{array}{c}a, b \\
b \\
b\end{array}$ \\
\hline 1 & A & ST2121 & $6,10,21,3,17,14,57$ & Bath 1 (bath water)ף & a \\
\hline 1 & $\mathrm{~B}$ & ST2114 & $6,10,21,3,17,14,9$ & $\begin{array}{l}\text { Patients 2, 5, } 7 \\
\text { Bath 1(bathtub swab) } \\
\text { Bath } 2 \text { (bath water)ף }\end{array}$ & $\begin{array}{c}b, b, b \\
b \\
b\end{array}$ \\
\hline 1 & $\mathrm{C}$ & ST1447 & $6,10,20,13,9,4,11$ & Bath 3 (hair trap debris) & C \\
\hline 13 & B & ST2113 & $6,10,21,10,17,14,209$ & $\begin{array}{l}\text { Patient } 2 \\
\text { Bath } 1 \text { (bath water)ף } \\
\text { Bath } 2 \text { (bath water) } \\
\text { Bath } 2 \text { (spout swab) }\end{array}$ & $\begin{array}{c}d \\
d \\
\text { Not done } \\
\text { d }\end{array}$ \\
\hline 10 & $\mathrm{D}$ & ST2115 & $7,10,17,3,13,14,207$ & $\begin{array}{c}\text { Bath } 4 \text { (spout swab) } \\
\text { Bath } 5 \text { (bathtub swab) }\end{array}$ & $\begin{array}{l}e \\
f\end{array}$ \\
\hline
\end{tabular}


genomic subtypes (patient 7) were detected. Results from 3 genetic methods revealed that $L$. pneumophila serogroup 1 and 13 strains are closely related, although the serogroups differ. Results of this study were consistent with the hypothesis that multiple infections are more likely with less virulent strains and more likely in persons with medical conditions predisposing them to Legionnaires' disease (10).

Our study of this outbreak suggests that the spa house was colonized by several L. pneumophila strains that were genetically related despite belonging to different serogroups and that 2 strains caused infection. Further analysis of the divergence of outbreak strains in genomes related to Legionella serogroup and sequence types is ongoing. This analysis clarifies the in-depth genetic relations among L. pneumophila strains, such as recombination sites and periods required for divergence. We recommend that the spa house provide high quality management and effective infection control practices according to an infection control manual (e.g., completion of documentation relating to infection control practices and training of employees) and that customers be aware of the sanitary status of spa houses.

\section{Acknowledgments}

We appreciate the help of the officers at Odawara Health and Welfare Center, who provided information on epidemiological studies.

This work was partly supported by Health and Labour Sciences Research (grant H25-kenki-009 to F. K.).

Dr. Kuroki is a director of the Department of Microbiology at Kanagawa Prefectural Institute of Public Health, Kanagawa, Japan. His research interests include epidemiology of protozoan and bacterial infectious diseases.

\section{References}

1. Yu VL, Stout JE. Community-acquired Legionnaires disease: implications for underdiagnosis and laboratory testing. Clin Infect Dis. 2008;46:1365-7. http://dx.doi.org/10.1086/586742

2. National Institute of Infectious Diseases and Tuberculosis and Infectious Diseases Control Division, Ministry of Health, Labour and Welfare. Legionellosis, April 1999-July 2000. Infect Agents Surveill Rep. 2000;21:186-7 [cited 2016 May 9]. http://idsc.nih.go.jp/iasr/21/247/tpc247.html

3. Yu VL, Plouffe JF, Pastoris MC, Stout JE, Schousboe M, Widmer A, et al. Distribution of Legionella species and serogroups isolated by culture in patients with sporadic community-acquired legionellosis: an international collaborative survey. J Infect Dis. 2002;186:127-8. http://dx.doi.org/10.1086/341087

4. Chang B, Amemura-Maekawa J, Watanabe H. An improved protocol for the preparation and restriction enzyme digestion of pulsed-field gel electrophoresis agarose plugs for the analysis of Legionella isolates. Jpn J Infect Dis. 2009;62:54-6 [cited 2016 May 9]. http://www0.nih.go.jp/JJID/62/54.html

5. Gaia V, Fry NK, Afshar B. Lück PC, Meugnier H, Etienne J, et al. Consensus sequence-based scheme for epidemiological typing of clinical and environmental isolates of Legionella pneumophila.
J Clin Microbiol. 2005;43:2047-52. http://dx.do.org/10.1128/ JCM.43.5.2047-2052.2005

6. Ratzow S, Gaia V, Helbig JH, Fry NK, Lück PC. Addition of neuA, the gene encoding $\mathrm{N}$-acylneuraminate cytidylyl transferase, increases the discriminatory ability of the consensus sequencebased scheme for typing Legionella pneumophila serogroup 1 strains. J Clin Microbiol. 2007;45:1965-8. http://dx.doi.org/ 10.1128/JCM.00261-07

7. Kozak NA, Benson RF, Brown E, Alexander NT, Taylor TH Jr, Shelton BG, et al. Distribution of lag-1 alleles and sequencebased types among Legionella pneumophila serogroup 1 clinical and environmental isolates in the United States. J Clin Microbiol. 2009;47:2525-35. http://dx.doi.org/10.1128/JCM.02410-08

8. David S, Mentasti M, Tewolde R, Aslett M, Harris SR, Afshar B, et al. Evaluation of an optimal epidemiological typing scheme for Legionella pneumophila with whole-genome sequence data using validation guidelines. J Clin Microbiol. 2016;54:2135-48. http://dx.doi.org/10.1128/JCM.00432-16

9. Qin T, Yan G, Ren H, Zhou H, Wang H, Xu Y, et al. High prevalence, genetic diversity and intracellular growth ability of Legionella in hot spring environments. PLoS One. 2013;8:e59018. http://dx.doi.org/10.1371/journal.pone.0059018

10. Balmer O, Tanner M. Prevalence and implications of multiplestrain infections. Lancet Infect Dis. 2011;11:868-78. http://dx.doi. http://dx.doi.org/10.1016/S1473-3099(11)70241-9

Address for correspondence: Toshiro Kuroki, Department of Microbiology, Kanagawa Prefectural Institute of Public Health, 1-3-1 Shimomachiya, Chigasaki, Kanagawa, 253-0087, Japan; email: kuroki.gcg3@pref.kanagawa.jp

\section{Diphyllobothrium nihonkaiense Tapeworm Larvae in Salmon from North America}

\section{Roman Kuchta, Mikuláš Oros, Jayde Ferguson, Tomáš Scholz}

Author affiliations: Biology Centre of the Academy of Sciences of the Czech Republic, České Budějovice, Czech Republic (R. Kuchta, T. Scholz); Slovak Academy of Sciences, Košice, Slovak Republic (M. Oros); State of Alaska Department of Fish and Game, Anchorage, Alaska, USA (J. Ferguson)

DOI: http://dx.doi.org/10.3201/eid2302.161026

Diphyllobothriosis is reemerging because of global importation and increased popularity of eating raw fish. We detected Diphyllobothrium nihonkaiense plerocercoids in the musculature of wild pink salmon (Oncorhynchus gorbuscha) from Alaska, USA. Therefore, salmon from the American and Asian Pacific coasts and elsewhere pose potential dangers for persons who eat these fish raw. 